\title{
MICROSCOPIC SIMULATION OF COORDINATED ROUTE IN THE CITY OF ZILINA
}

Urban agglomerations are characterized by concentrating a large number of vehicles in a confined space, while it is not possible to increase the range of the road communications. Therefore, it is necessary to achieve better and more efficient use of existing communications. Creation of successful city management means to integrate and optimize the quality of transport. When intersection signal control is used, not only the high degree of safety is ensured, but also permeability of the intersection increases. For better and more effective use of intersections we use a management in real time. We model the program of management by microscopic simulation. In our paper we use simulation of coordination at intersections in the city of Zilina. As modeling tools we use software Aimsun and MATSim which allow microscopic simulation. Finally, in our paper we compare both of the software tools.

Keywords: Microscopic simulation of intersections, AIMSUN, MATSim.

\section{Introduction}

Due to needs of changing mobility demands of population, cities or villages must adapt and create suitable transport infrastructure which will be able to fulfill the demands placed on it and have to introduce measures that will help to make effective of use the transport infrastructure. One of these measures can be reconstruction and building modifications of road communications and a new organization of transport. These activities are logically associated with high financial costs and with certain risk that the new measures will not bring a desired effect. The increase of individual transport, which is more comfortable for its users, especially in time of traffic peak in cities with high intensity of transport flow, has a negative impact on transport quality and environment, emergence of congestions, formation of the exhaust gases, noise, decreasing of road safety, slowing traffic, delay of vehicles at intersections, etc. [1].

Foreign expert studies say that the dynamic management of transport will improve permeability of intersections in the range of $20-30 \%$ compared to the management with fixed signal plans [2].

The issue of management and regulation of urban traffic is one of the most important areas in urban agglomerations. The development of transport has achieved the degree that without thorough revision of management system and regulation, transport collapse would occur in short-time, which would have a negative impact on the other fields of life in city and its inhabitants. Keeping the intensity and safety of vehicles movement along the streets which doesn't endanger the life of the city itself is a task that must be dealt with highest priority, mainly with the help of macroscopic simulation. The base is modeling of vehicles driving within existing communication network, while all parameters of infrastructure and vehicles, including the drivers' behavior are respected [3 and 4].

\section{Characteristic of the analyzed area}

Velka Okruzna Street with its length of about $1.5 \mathrm{~km}$ is one of the most important road communications in the city of Zilina. It starts at the junction of streets - Velka Okruzna and 1. Maja and ends at the Murgasova Street. In the past it was an important transport corridor which led traffic from Strecno (today road I/18) to Halkova Street and Rondel and fly-over which roads from Prievidza, Cadca and Bratislava were connected to. Currently Velka Okruzna Street consists of two-lane urban roads and junctions at grade. It is a distributor road of the urban roads category B1 and together with the streets P. O. Hviezdoslava, 1. Maja, Hurbanova, Legionarska and Kalov creates the second ringroad of Zilina. Velka Okruzna Street itself is situated in the central part of the city - see Fig. 1.

\footnotetext{
* Alica Kalasova, Lubomir Cernicky, Simona Kubikova

Department of Road and Urban Transport, Faculty of Operation and Economics of Transport and Communications, University of Zilina, Slovakia, E-mail: alica.kalasova@fpedas.uniza.sk
} 


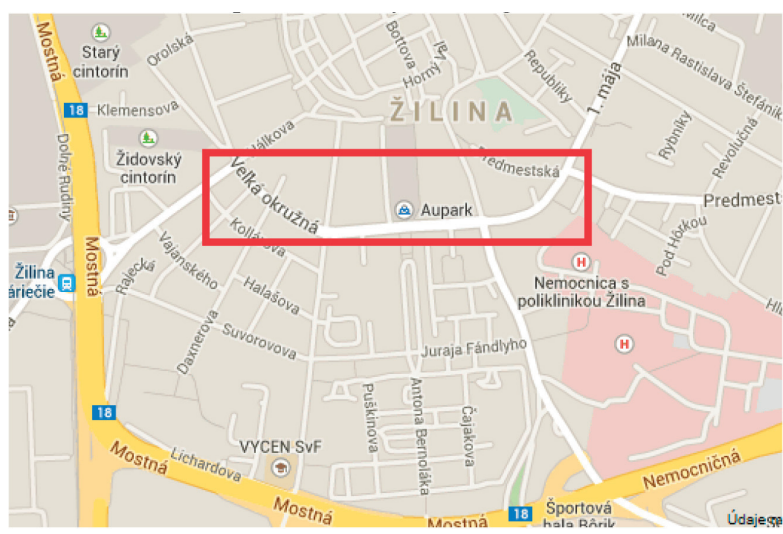

Fig. 1 Situation of Velka Okruzna Street in the city Source: authors using Google maps

Over 10,000 vehicles pass through this street daily, while an hour traffic volumes come up to $800 \mathrm{veh} /$ hour [5]. In our department within practical exercises in transportation engineering, we regularly carry out the road traffic surveys on these intersections. In the last 10 years the intensity has increased by $7.54 \%$ - at the junction of Velka Okruzna - Komenskeho streets and in average by $14.21 \%$ at the chosen communication. Figure 2 shows the traffic peak intensities of traffic flow at the chosen part of Velka Okruzna street. In addition, almost all public transport lines cross or at least pass through this street.

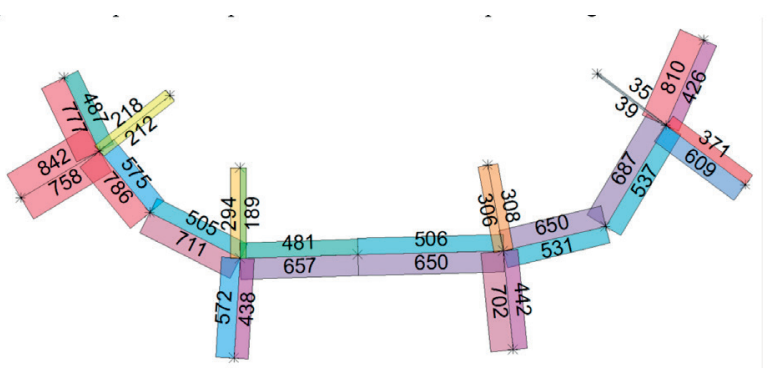

Fig. 2 Rush-hour rate at the chosen part of Velka Okruzna street Source: authors

\section{Modeling of transport at junctions}

The advantage of simulation techniques is that they allow insight into existing system without its disruption, as well to repeat the whole simulation process according to needs and modify input data both in real time and in expedited time. With the progress in field of computer technology and with selecting the appropriate tool or software it is possible to model and simulate more and more extensive network. The base of microscopic simulation is to find optimal relation to every single situation and to verify it empirically, which is nearly always complicated. Compared with the conventional calculations, it allows much better approximation to reality and also much easier and better verifiable entering of the input data.

a) Aimsun

Other modeling tool we used was AIMSUN software tool (Advanced Interactive Microscopic Simulator for Urban and Non- Urban Networks) of a Spanish company TSS (Transport Simulation Systems) which is able to reproduce on computer real traffic conditions in any transport network. It is designed especially for testing new control systems.

By simulation in this program it is possible to get a lot of outputs which are divided into groups: statistics for the whole network, statistics for sections and turns, statistics for the chosen road, statistics for matrix source/destination and statistics for public transport. Outputs such as the average intensity, density, mean speed, section speed, travel time, delay time, stop time, number of stops, total traveled distance, total travel time, fuel consumption and quantity of produced emissions are generated for each group. The differences between particular groups are in requirements on input data and in units in which the outputs are calculated [6].

\section{b) MATSim Multi-Agent Transport Simulation}

MATSim, standing for Multi- Agent Transport Simulation, is a free transport planning software developed in Germany (Berlin Institute of Technology) and Switzerland (Swiss Federal Institute of Technology Zurich) and is used all around the world including Poland, Singapore, Indonesia, Canada, South Africa, Israel, Japan [7].

MATSim provides a framework for implementing large-scale agent-based transport simulations. The framework consists of several modules which can be combined or used stand-alone. Modules can be replaced by their own implementation to test single aspects of their own work. Currently, MATSim offers both framework for demand-modeling, agent-based mobility simulation (traffic flow simulation), re-planning, and a controller to iteratively run simulations as well as methods to analyze the output generated by the modules.

\section{Key Features of MATSim}

- Fast Dynamical and Agent- Based Traffic Simulation: Simulates whole days within minutes,

- Private and Public Traffic: Both private cars and transit traffic can be simulated,

- Supports Large Scenarios: MATSim can simulate millions of agents or huge, detailed networks,

- Versatile Analyses and Simulation Output: E.g. compares simulated data to real- world counting stations,

- Modular Approach: Easily extended with your own algorithms,

- Interactive Visualizer: See what each agent is doing during the simulation, 
- Open Source: You get the Java Source Code which runs on all major operating systems,

- Active Development: We add constantly new features and improve current ones [7].

The outputs of simulation by default are graphic and text files which are very useful for initial analysis [7]:

- Score Statistics- as an image or text file- the best, average, the worst results of agent for each iteration

- Leg Travel Distance Statistics - is comparable to the score statistics, but instead of the score, the travel distance is ploted.

- Stopwatch - contains the duration of all actions for every iteration.

- "Leg“ histogram- depicts the number of agents that arrive, depart or are en route per time unit. Histograms are created for each transport mode and, additionally, for the sum of all transport modes.

- Trip Durations - the number of trips and their durations on a time bin level for each activity pair (work - home, home shopping, etc.)

- In addition it is possible, in the range of application programming (API - Application Programming Interface) to insert own logic to the model and get other outputs [7].

\section{Comparison of macroscopic simulations}

As we mentioned, we solved coordination on communication Vel'ká Okružná street with microscopic simulation in two variants: junctions with traffic signal control equipment, junctions without traffic signal control equipment where two different transportplanning modeling softwares Aisum and MATSim were used. a) Creation of model

We can say that the creation of a transport model in both of the programs consists of two main parts:

- Creation/description of the transport network (nodes, sections, junctions, possible turnings, maximal speed on sections, etc., transport management, etc.)

- Creation/description of the travel demand (the volume of single sections- matrix source/destination, description of public transport routes)

In creation of a transport model in both of the modeling tools, the same inputs were used:

- Map bases, number and widths of driving lanes, intensity and direction of transport in single entrances to junctions (which were obtained from road traffic survey which was made by University of Žilina), characteristics of particular vehicles and junctions signal plans.

- For transport generating in both of the cases, the exponential function was used.

The difference in creation of transport network was that in the modeling program Aismsun the modeling network was created ",by hand" in a user-friendly drawing editor, whereas it was imported into the MATSim from freely available maps (OpenStreetMap and Geofabrik), specifically from the file OpenStreetMap data for Slovakia [8]. The next difference was in definition of light signalization where Aimsun offers a wide range of possibilities and allows to simulate also adaptive control systems such as SCATS, VS- PLUS, preference for public transport, while the module for modeling of road traffic control equipment in transport networks in MATSim was an unsupported function during carrying out this study (26.07.2013), there was only a basic code which allows only simulation of road traffic control equipment with fixed signal plans [8].

Aimsun outputs

Table 1

\begin{tabular}{|c|c|c|c|c|c|c|}
\hline \multirow[t]{2}{*}{ Simulation outputs } & \multicolumn{2}{|c|}{ Value } & \multirow{2}{*}{ The difference } & \multirow{2}{*}{ Unit } & \multirow{2}{*}{\multicolumn{2}{|c|}{ Relative difference }} \\
\hline & without TLE & with TLE & & & & \\
\hline Delay Time & 35.57 & 108.16 & 72.59 & $\mathrm{sec} / \mathrm{km}$ & 204.08 & $\%$ \\
\hline Density & 8.91 & 15.12 & 6.21 & $\mathrm{veh} / \mathrm{km}$ & 69.70 & $\%$ \\
\hline Flow & 4067.43 & 4088.29 & 20.86 & veh/h & 0.51 & $\%$ \\
\hline Harmonic Speed & 35.45 & 20.67 & -14.78 & $\mathrm{~km} / \mathrm{h}$ & -41.69 & $\%$ \\
\hline Speed & 41.42 & 25.72 & -15.7 & $\mathrm{~km} / \mathrm{h}$ & -37.9 & $\%$ \\
\hline Total Distance Traveled & 2494.07 & 2495.46 & 1.39 & $\mathrm{~km} / \mathrm{h}$ & 0.06 & $\%$ \\
\hline Total Travel Time & 68.17 & 11563 & 47.46 & $\mathrm{~h}$ & 69.62 & $\%$ \\
\hline Travel Time & 101.84 & 174.48 & 72.64 & $\mathrm{sec} / \mathrm{km}$ & 71.33 & $\%$ \\
\hline
\end{tabular}

Source: authors 


\begin{tabular}{|c|c|c|c|c|c|c|}
\hline \multirow{3}{*}{$\begin{array}{l}\text { Simulation outputs } \\
\text { Delay Time }\end{array}$} & \multicolumn{2}{|c|}{ Value } & \multirow{3}{*}{$\begin{array}{c}\text { The difference } \\
5.75\end{array}$} & \multirow{3}{*}{$\begin{array}{c}\text { Unit } \\
\mathrm{sec} / \mathrm{km}\end{array}$} & \multirow{2}{*}{\multicolumn{2}{|c|}{ Relative difference }} \\
\hline & \multirow{2}{*}{$\begin{array}{c}\text { without TLE } \\
272.32\end{array}$} & \multirow{2}{*}{$\begin{array}{r}\text { with TLE } \\
278.07\end{array}$} & & & & \\
\hline & & & & & 2.11 & $\%$ \\
\hline Density & 8.32 & 8.34 & 0.02 & $\mathrm{veh} / \mathrm{km}$ & 0.24 & $\%$ \\
\hline Flow & 7014.4 & 7013 & -1.4 & veh/h & -0.02 & $\%$ \\
\hline Harmonic Speed & 5.26 & 5.18 & -0.08 & $\mathrm{~km} / \mathrm{h}$ & -1.52 & $\%$ \\
\hline Speed & 30.63 & 29.41 & -1.22 & $\mathrm{~km} / \mathrm{h}$ & -3.98 & $\%$ \\
\hline Total Distance Traveled & 2347.14 & 2347.12 & -0.02 & $\mathrm{~km} / \mathrm{h}$ & 0 & $\%$ \\
\hline Total Travel Time & 241.81 & 246.48 & 4.67 & $\mathrm{~h}$ & 1.93 & $\%$ \\
\hline Travel Time & 370.86 & 378.02 & 7.16 & $\mathrm{sec} / \mathrm{km}$ & 1.93 & $\%$ \\
\hline
\end{tabular}

Source: authors

Comparison of outputs of Aimsun - MATSim

Table 3

\begin{tabular}{|c|c|c|c|c|c|c|}
\hline \multirow{3}{*}{$\begin{array}{l}\text { Simulation outputs } \\
\text { Delay Time }\end{array}$} & \multicolumn{2}{|c|}{ Value } & \multirow{3}{*}{$\begin{array}{c}\text { The difference } \\
169.91\end{array}$} & \multirow{3}{*}{$\begin{array}{c}\text { Unit } \\
\mathrm{sec} / \mathrm{km}\end{array}$} & \multirow{2}{*}{\multicolumn{2}{|c|}{ Relative difference }} \\
\hline & \multirow{2}{*}{$\begin{array}{r}\text { Aimsun } \\
108.16\end{array}$} & \multirow{2}{*}{$\frac{\text { MATSim }}{278.07}$} & & & & \\
\hline & & & & & 157.09 & $\%$ \\
\hline Density & 15.12 & 8.34 & -6.78 & $\mathrm{veh} / \mathrm{km}$ & -44.84 & $\%$ \\
\hline Flow & 4088.29 & 7013 & 2924.71 & veh/h & 71.54 & $\%$ \\
\hline Harmonic Speed & 20.67 & 5.18 & -15.49 & $\mathrm{~km} / \mathrm{h}$ & -74.94 & $\%$ \\
\hline Speed & 25.72 & 29.41 & 3.69 & $\mathrm{~km} / \mathrm{h}$ & 14.35 & $\%$ \\
\hline Total Distance Traveled & 2495.46 & 2347.12 & -148.34 & $\mathrm{~km} / \mathrm{h}$ & -5.94 & $\%$ \\
\hline Total Travel Time & 115.63 & 246.48 & 130.85 & $\mathrm{~h}$ & 113.16 & $\%$ \\
\hline Travel Time & 174.48 & 378.02 & 203.54 & $\mathrm{sec} / \mathrm{km}$ & 116.66 & $\%$ \\
\hline
\end{tabular}

Source: authors

\section{b) Outputs of modeling}

The following statistics was chosen and compared for our purposes: delay time, density, traffic flow, section speed, mean speed, total distance traveled by all vehicles, total time traveled by all vehicles, travel time.

There are simulations outputs of Aimsun modeling program in Table 1, the simulation outputs of MATSim modeling program are in Table 2. The third table (Table 3) compares simulation outputs in both of the modeling programs.

The results of simulation in Aimsun modeling program (see Table 1) show better statistics for network without traffic lights equipment (TLE), for example, delay time for this network is lower by $72.59 \mathrm{sec} / \mathrm{km}$, which represents the difference of more than $200 \%$ and mean speed of vehicles without traffic lights equipment would be higher by nearly $38 \%$. The reasons for these differences are as follows:

- Junctions are in coordination. For our period of modeling (15:00 - 16:00) they are set to cycle $109 \mathrm{~s}$ and in most of the junctions (except junction Velka Okruzna - Komenskeho) there is a four- stroke control.
- Signal plans of junctions (also signal plan of light controlled pedestrian crossing at Dom odborov) are designed to ensure safe pedestrian crossing at every contemplated junction and, therefore, the implementation of signal plans to our model was included with pedestrians which the variant without traffic lights equipment ignores.

The same as in Aimsun modeling program also in MATSim modeling program were simulated and compared variants with or without traffic lights equipment. The outputs of this modeling program showed different values as the outputs of Aimsun modeling program. In Table 2 we can see only slight change between variants with and without traffic lights equipment $(2.11 \%$ increase of delay time, $3.98 \%$ decrease of speed, etc.) and in Table 3 we can see the differences in simulation outputs of both Aimsun and MATSim modeling programs.

The reasons for these differences can be seen in the following factors:

- Setup of MATSim allows setting an adjustable flow capacity and storage capacity factor which is set on the base of empiric 
results for the whole network. These factors are preset to value 1.0 and the results of simulation are very sensitive to their change. In our paper this factor with the value of 2.0 was used because these settings provide more realistic results, but to capture real-time status further adjustments of this factor would be required.

- The module for modeling traffic lights equipment at transport networks in MATSim- was an unsupported function during carrying out this study on 26 th of July 2013, there was only a basic code which allows only simulation of road traffic control equipment with fixed signal plans.

- Finally, the differences could have been caused by different creation of model of transport network where in modeling program Aimsun the network was created manually, whereas in MATSim it was imported from the maps [7].

\section{Conclusion}

As we mentioned, recently there has been tremendous growth in road transport which has great demands on the accessibility of the city. Constantly increasing traffic results in growth in number of congestions, increasing idle times and environmental damage [9]. Traffic modeling helps to manage all these problems. Traffic modeling doesn 't include only traffic simulation, but it is a wide range of tools ranging from simple application for only one purpose to complex tools which enable to perform complicated analysis of transport networks. Then the outputs can be easily understandable models which can be implemented into the real environment and which provide relevant information. One of the disadvantages of traffic modeling is the fact that a traffic model and simulation don't solve the problem. The outputs of the simulation can only indicate the correct way of solving the problem. Traffic modeling can be used to many operations and there is assumption that the importance of the traffic modeling will be increasing with the increase of transport. In our study traffic modeling confirmed improvement of traffic situation after the coordination of signal controlled junctions in the particular Slovak town and also traffic modeling was shown as a convenient tool in creation process of further transport solutions.

\section{Acknowledgement:}

VEGA Project No. 1/0159/13 - KALASOVA, A. and collective: Basic Research of Telematic Systems, Conditions of Their Development and Necessity of Long-term Strategy. University of Zilina, the Faculty of Operation and Economics of Transport and Communications, 2013-2015.

Centre of excellence for systems and services of intelligent transport II,

ITMS 26220120050 supported by the Research \& Development Operational Programme funded by the ERDF.

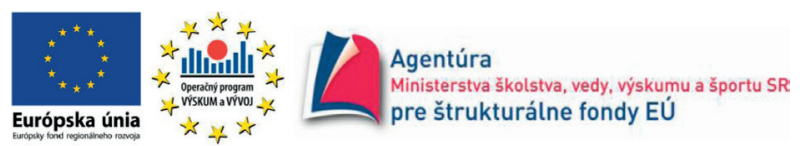

„Podporujeme vyskumne aktivity na Slovensku/Projekt je spolufinancovany zo zdrojov EU“

\section{References}

[1] KAlasoVA, A., KUPCUlJAKOVA, J.: The Future in the Telematics Applications as Support for Increased Safety. Transport Problems, vol. 7, No. 1, pp. 103-110.

[2] JAGELCAK, J.: Equation of the Standard EN 12195-1 Stipulates Unreasonable Demands for Cargo Securing, Communications Scientific Letters of the University of Zilina, vol. 9, No. 4, 2007, pp. 30-33, SCOPUS, ISSN 1335-4205

[3] KUBASAKOVA, I., SULGAN, M.: Using the Intelligent Systems for Transport and Logistics. LOGI Scientific J. on Transport and Logistics, No. 1, 2013 Institute of Jan Perner, Pardubice, pp. 86-94, ISSN 1804-3216.

[4] ONDRUS, J., DICOVA, J.: Prediction and Analysis of Motorization Rate Development in Chosen Districts of Slovak Republic, Archives of Transport System Telematics, vol. 6, No. 3, 2013, pp. 26-32, ISSN 1899-8208.

[5] Urban Plan of City of Zilina, Available at the internet: http://www.zilina.sk/docs/ 2012/ upm_zilina/Obligatory_part_text.pdf; http://www.acea.be (The European Automobile Manufacturers Association).

[6] TSS - Transport Simulation Systems. Aimsun 7 Dynamic Simulators User's Manual May 2012.

[7] http://matsim.org/ on September 2nd, 2013

[8] http://download.geofabrik.de/europe/slovakia.html

[9] SOSEDOVA, J., SLESINGER, M., BARIAK, M.: Telematics in Inland Navigation. Communications - Scientific Letters of the University of Zilina, vol. 12, No. 3, pp. 66-68, 2008, ISSN 1335-4205. 